\title{
INDUSTRY 4.0 - POLICY-BASED APPROACHES TO EFFICIENT IMPLEMENTATION IN SMES
} pages: $72-78$

\author{
JOANNA ŁABĘDZKA
}

\begin{abstract}
A B S T R A C T
Industry 4.0 (14.0), driven by the need to access real-time insights and information across the manufacturing process, creates a disruptive impact on industries. Largescale machine-to-machine communication, virtual reality (VR), the Internet of Things (IoT), simulation technologies and network management are integrated for increased automation, machine learning, self-controlled social and technical systems (Smart Factories). The uptake of advanced manufacturing solutions represents a challenge for businesses and SMEs in particular. SMEs possess neither the organisational capability nor financial resources to systematically investigate the potential and risks of introducing Industry 4.0. However, the so-called Fourth Industrial Revolution is a matter of technology and cooperation between European regions to share knowledge concerning alternative regional and national approaches to reinforcing the 14.0 uptake. Therefore, this paper primarily aims to analyse practical experience on how European policies related to the European Regional Development Fund (ERDF) can unlock the full potential of Industry 4.0 and overcome the fragmentation of Industry 4.0 solutions. Case studies of successful transfer of 14.0 to SMEs in Europe and supporting regional policy instruments presented in the paper could inspire and enable the potential of digitalisation by dealing with main challenges hampering their diffusion into the business ecosystem.
\end{abstract}

KEY WORDS

Industry 4.0, digital transformation, SMEs, structural funds, policy instruments

10.2478/emj-2021-0032
Corresponding author

Joanna Łabędzka

Sieć Badawcza Łukasiewicz - Instytut Technologii Eksploatacji, Poland ORCID 0000-0003-1409-7926 e-mail: joanna.labedzka@ujk.edu.pl

\section{INTRODUCTION}

The transformation of industrial production is a new economic paradigm in which material wealth is not delivered perforce at the expense of growing environmental risks, ecological scarcities and social disparities (United Nations Environment Programme, 2011). Industry 4.0 might offer an enormous chance to align the sustainable development goals with the ongoing digital transformation in industrial development (Beier et al., 2020). It is expected that

Łabędzka, J. (2021). Industry 4.0 - policy-based approaches to efficient implementation in SMEs. Engineering Management in Production and Services, 13(4), 72-78. doi: 10.2478/emj-2021-0032 
the development of Industry 4.0 will contribute to tackling global challenges by achieving better resource- and energy efficiency and strengthening the competitiveness of high-income countries (Rauch et al., 2018).

The core principles of I4.0 are modularisation, self-regulation, and digital integration across business functions and within and beyond the organisational boundaries (Prause, 2019) based on the Internet of Things (IoT) (Atzori, Iera, \& Morabito, 2010) and cyber-physical systems (Khaitan \& McCalley, 2015).

With the advent of newer developments, including artificial intelligence, 3D printing and robotics, yet more profound changes are anticipated in the years and decades to come (Ramalingham et al., 2017).

Companies across the globe are digitally transforming as they are challenged to improve processes and develop new capabilities and business models. Large companies are anticipating the changes arising from the digital revolution in the production and value creation process more easily, while small and medium-sized enterprises (SMEs) are struggling to embrace the Industry 4.0 revolution (Azevedo \& Almeida, 2021).

Only $17 \%$ of SMEs have successfully integrated digital technologies into their businesses, compared to $54 \%$ of large companies (Digital Innovation Hubs Working Group, 2018). And yet, the successful implementation of an industrial revolution has to occur not only in large enterprises but in SMEs in particular (Sommer, 2015).

However, the transformation of the European manufacturing business towards I4.0 is not only a matter of technology but also a matter of cooperation between regions to share knowledge concerning policy instruments at the regional and national level to assist this process, especially in small and medium enterprises. Several different types of constraints can affect this process in SMEs and should be considered.

The paper's author wishes to present inspiring good practice on policy instruments supporting the transfer of digital development in SMEs that is critical to achieving the competitiveness and vision of accelerating sustainability and building a green economy. The research presented in the paper intends to analyse experience on how policy related to Structural Funds can unlock the potential of Industry 4.0 in SMEs and answer the key question: What are effective policy instruments to reinforce the Industry 4.0 uptake in SMEs?

\section{LITERATURE REVIEW}

Small and medium-sized enterprises are the foundation of the growing economy. The European Commission considers SMEs and entrepreneurship essential in ensuring economic growth, innovation, job creation, and social integration in the EU (Papadopoulos et al., 2020; European Commission, 2021). SMEs create two out of three jobs, generate $50 \%$ of the EU's GDP and play a crucial role in adding value in every economic sector (Borowicz, 2021).

Given that SMEs are a major driver of the European economy, accounting for most firms and creating large shares of employment and value-added, the digital transformation is a matter of their market position (European SME Survey, 2019). SMEs in Europe risk their future in the case of failure to embrace digitalisation, as more than one in two SMEs are concerned that they may lose competitiveness if they do not adopt new digital technologies (Azevedo \& Almeida, 2021).

The digital revolution is still a challenge to SMEs as they are regarded as less well-prepared for the new technologies and standardisation problems and may face particular barriers in implementing I4.0.

Researchers have indicated several barriers that could constrain SMEs in the adoption of innovations, including I4.0 solutions, for example, the lack of awareness concerning digital capabilities, cybersecurity issues, limited financial resources, inflexibility to change, strategic aspects, technological intensity, aversion to innovation, unclear I4.0 implementation details, insufficient or lacking capacity to test industrial solutions, including limited access to facilities (Horvath \& Szabo, 2019; Saunila, 2020; Prause, 2019; Alcacer \& Cruz-Machado, 2019; Galati \& Bigliardi, 2019; Marchuk, 2021; Jovanovski et al., 2019).

Another reason for SMEs to likely refrain from implementing I4.0 technologies is related to new production and product development technologies and has a competence-based explanation (Yu \& Schweisfurth, 2020; Ingaldi \& Ulewicz, 2020). Some decisionmakers renounce digital transition simply because they do not understand how it can be incorporated into the business (Azevedo \& Almeida, 2021).

The lack of support and guidance from the best practices in adopting new technologies in SMEs was also one of the main barriers. Traditional SMEs are often uncertain in their choice of digital business strategy, have problems tapping into large extensive data repositories available to larger companies and shy 
away from advanced AI-based tools and applications (EU's SME Strategy for a sustainable and digital Europe Communication, 2020). SMEs' access to information must be improved to stimulate the transfer of technology.

The role of the government as an enabler of SMEs in the implementation process cannot be ignored (Jovanovski et al., 2019). The importance of I4.0 transfer to SMEs has been recognised by the European Commission (EC) that has published numerous documents and studies on digitalisation (Davies, 2015; Probst et al., 2018; European Commission, 2018; European Commission, 2020). In addition, the EC has earmarked EUR 80 billion in the period $2014-2020$ for research and innovation, including help for the development of key enabling technologies to encourage local, regional, and national governments to develop different financial and non-financial support for reindustrialisation and increasing the competitiveness of the EU (Borowicz, 2021).

Also, the European Regional Development Fund (ERDF), under the umbrella of the European Union programme Interreg Europe, co-funded the project entitled "Smart SMEs for Industry 4.0" (acronym SMARTY) to overcome the research gap and help regional and local governments across Europe to develop and deliver a better policy. The international research network is composed of EU regions: Tuscany (Italy), Flanders (Belgium), Lapland (Finland), Mazovia (Poland), Slovenia, Castilla y León (Spain), Catalonia (Spain), Leeds City Region (UK). The paper presents research realised within the SMARTY project focused on sharing solutions and policy learning on alternative approaches to successfully implementing Industry 4.0 in SMEs.

\section{Methodology}

The main research method used in the paper is a case study based on an investigation of the regional/ national policy instruments that help to reinforce the Industry 4.0 adoption in small and medium manufacturing enterprises. The case study method was selected as its advantages overshadow the limitations of statistics-based research methods, such as surveys, interviews or experiments, and it is suitable for developing theories in design research (Teegavarapu et al., 2008).

The following steps were employed in the case study approach: (1) research justification, (2) the justification of the case study method, (3) criteria for selecting a case, (4) data collection, (5) case study analysis. A descriptive case study (Stake, 1995) was designed to answer the research question.

The cases were identified in the learning process within the SMARTY project in the following thematic domains: (1) clusters and clustering initiatives, (2) Digital Innovation Hubs (DIHs), and (3) Digitalisation for Green Transition and Sustainability. The presented investigation was relevant because it fosters knowledge-sharing about alternative measures to face the challenges and overcome obstacles that hamper SMEs' digital transformation.

The presented cases are based on the regional experiences on I4.0 transfer and were shared by their owners within international seminars to inspire other European regions and countries, so the interregional exchange of experience and transfer of knowledge can be applied in other regional and business systems. Each case was then reviewed and assessed by, among others, the representatives of those regions, entrepreneurs, stakeholders, I4.0 experts, career advisors, considering the following aspects: (a) the track record/ results/impact/success of a case, (b) the potential of transferability, and (c) special interest/relevance for other regions. Cases with the highest ranking were selected for detailed description, confirmed as good practice of I4.0 transfer to SMEs and will be transferred to action plans and recommendations for public policies.

\section{RESEARCH RESULTS}

The first policy instrument is an example of a cluster-centred approach that plays a significant role as a driver of regional innovation and the ability to increase collaboration in the Industry 4.0 ecosystems. The Future Industry Platform (https://przemyslprzyszlosci.gov.pl) is a State Treasury Foundation established by the Polish Ministry of Entrepreneurship and Technology in response to the low level of knowledge and awareness of the SMEs regarding the potential of digital transformation, especially new technologies in production processes and modern business models. The platform financing is based on the annual subsidy established by the Ministry.

The low level of knowledge and awareness of SME management regarding the potential of advanced technologies is one of the main barriers to the implementation of I4.0; therefore, the platform was created to strengthen the competences of I4.0 employees of enterprises operating in Poland. To reach this objective, the platform offers training programmes and 
innovative ways to demonstrate and explain I4.0 technological solutions to entrepreneurs. Free of charge, thematic workshops are organised in all voivodeships in Poland to provide access (for managers and business owners) to basic knowledge concerning business models, change management at the strategic level and transfer of I4.0 solutions to production.

Creating knowledge and experience exchange processes that ensure access to the international community and experts in the field of digital transformation is one of the results achieved by the platform.

The digital transformation towards I4.0 is also a matter of cooperation and co-creation of new values; therefore, the platform creates a network of partner organisations to scale its activities, for example, Registered Training Organisations (RTOs), clusters, chambers of commerce, DIHs, and direct support for SMEs: training, consultancy, webinars, and expert studies.

To reinforce the uptake of digital transformation and implementation of digital products and services, in SMEs in particular, the platform also helps to introduce business models based on intelligent data analysis, automation, process virtualisation, and cybersecurity.

Interestingly, the Future Industry Platform designed an online self-assessment tool to assess the digital maturity of companies (available in Polish at the Future Industry Platform web page: https:// przemyslprzyszlosci.gov.pl/) interested in digital transformation. The tool investigates the following key pillars of enterprise development towards Industry 4.0:

- Processes - scan questions refer to product life cycle integration, ecosystem integration, internal integration, and standardisation;

- Technologies - scan questions refer to connectivity, automation, autonomisation, and intelligent product; and,

- Organisation - scan questions refer to leadership, employees, strategy cooperation, and projects.

The main aim of the scan is to determine the real level of digital transformation of the company, identification of challenges and necessary changes (individual recommendations for a company are prepared after the scan completion) to align standards in the context of I4.0.

The case of the Future Industry Platform may be of interest to other regions because of its transferability potential to different levels of application: national, regional, and organisational. The platform also builds the awareness of the Industry 4.0 benefits for SMEs, stimulates the activities of individual enterprises towards digitisation and integrates business units, especially SMEs, that can positively boost their capacity to absorb I4.0 technologies. Moreover, the case presented strengths of the business sector by creating mechanisms for cooperation between different stakeholders like RTOs, educational institutions, technology providers and local governments by sharing knowledge and building trust in relationships between market entities involved in the digital transformation process.

Cluster initiatives, such as the Future Industry Platform, must be focused on establishing a robust and regenerating ecosystem that produces the innovation, talent, and economic opportunities that firms need to thrive. The focus is fostering innovation through the development of the ecosystem and supporting SMEs for restructuring, modernisation and knowledge acquisition.

The following case of the regional and national facilitation of I4.0 transfer to SMEs describes the EC's initiative, the Digital Innovation Hub (DIH). DIH is a regional-based platform that facilitates public-private partnerships to co-design policy initiatives resulting from co-participation and negotiation of spatially-bound oriented initiatives for digitising. DIHs may offer several public-private collaboration models to its business partners (SMEs, entrepreneurs, large corporations), for instance: piloting and codesign of new services (proof-of-concept work, prototyping), training and support (technical consultancy, commercialisation), visibility (networking to expand beyond local markets).

Catalonia's Digital Innovation Hub (DIH4CAT) is a non-profit regional ecosystem led by the Generalitat of Catalonia through the Department of Digital Policies and Public Administration and the Department of Business and Knowledge. The Hub integrates the main parties involved in the digital transformation process and fits perfectly into the Catalan landscape as Catalonia has become a major European innovation hub for digital and biomedical technology. As a result of coordination actions and specific growing instruments, over 1000 SMEs were technologically transformed between 2019 and 2021. Pro-digital actions in Catalonia included: mapping of technology capacities and sector technological needs, coordination actions to improve players' efficiency, mapping technology capacities and sector technological needs, and specific programmes to support SMEs in the digitalisation process. 
The DIH4CAT connects seven strategic nodes:

- artificial intelligence (AI) - over 170 AI companies employing over 8000 workers with a turnover of EUR 1358 million.

- supercomputing - the main objective is to create a scientific infrastructure of excellence.

- cybersecurity - 356 companies specialising in cybersecurity in Catalonia employing over 6000 workers with a turnover of EUR 808 million.

- smart connectivity - 38 companies specialising in smart connectivity, 150 workers in $5 \mathrm{G}$ technology jobs, 251 IoT companies with over 3000 workers.

- $\quad$ additive manufacturing and 3D print -118 specialised companies employing over 1300 workers with a turnover of EUR 325 million.

- robotics and advanced manufacturing - 147 robotics companies, 391 circular economy companies with 70419 workers; and,

- photonics - 60 laboratories and nine spin-off companies, Cluster SECPHO with more than ten partners.

Each node is coordinated by an RTO or a university and offers a complete portfolio of technology and business services concerning awareness and diagnosis, transformation plan, training, prototype and testing, and networking. The DIH4CAT is a one-stop shop that supports all services along the commercialisation process, from the concept of innovation, through prototyping, training to market expansion. Primary Catalonia's objective is to help SMEs become "digitised and connected, sustainable, and integrated". The Hub works as a dynamic community integrating stakeholders with capabilities in digital technologies and Industry 4.0 and improves their skills and knowledge through its regional and international interconnection with ecosystem actors.

The presented DIH4CAT helps foster the transition into Industry 4.0 and facilitates a new path development. Its ambition is not only to deliver userfriendly and targeted advice on sustainability and digitalisation but also to connect support structures so that every SME has advice nearby. The DIH4CAT creates the ecosystem and works closely with other DIHs and stakeholders to ensure a seamless support and advice service, including with national, regional and local authorities and support structures.

Digitalisation for Green Transition and Sustainability refers to the process of digitalising the economy in a long-lasting, green, and organic way. The next policy instrument highlights incentives for $\mathrm{R} \& \mathrm{D}$ projects for the productive reconversion within the circu- lar economy that has been introduced in Italy by the Ministry of Economic Development (MISE). The initiative's main aim is to introduce innovative production processes and solutions for the green transition in accordance with the circular economy and the digitalisation process in support of the green economy objectives. As a result, $\mathrm{R} \& \mathrm{D}$ projects leading to more efficient and sustainable use of available resources are co-financed.

The budget available for this measure is EUR 140 million, of which EUR 100 million for the concession of subsidised loans and EUR 40 million in the form of direct contributions to the expenditure. The nominal percentage of the eligible costs for SMEs is $11-20 \%$, and $10 \%$ for large companies. The projects eligible for subsidies must focus on industrial research and experimental development activities, aimed at the productive conversion of economic activities through the creation of new products, processes or services or to significant improvement of existing products, processes or services, through the development of the key enabling technologies, including, among others, ICT, advanced manufacturing and processing.

The main supported activities are as follow:

- product and process innovations based on the efficient use of resources and "zero waste" transformation considering circular economy standards or/and environmental compatibility (eco-compatible innovations).

- experimental design and prototyping of a technological model aiming to enforce the dual industrial pattern.

- innovative technological tools to increase the life span of products and the efficiency of the productive cycle.

- smart packaging experimentation through the utilisation of waste material.

- systems, tools and methodologies for the development of technologies for the supply, rational use and sanitation of water.

- systems for the selection of super-light material to enhance the recovery of and recycle small and light materials.

Submitted proposals are evaluated by the National Agency for Inward Investment and Economic Development (Invitalia), and the technical-scientific evaluation is made by the National Agency for New Technologies, Energy and Sustainable Economic Development (ENEA) and then recommended to the Ministry for financing. The incentives for R\&D projects for the productive reconversion within the circular economy help companies invest and develop new 
environmentally-friendly products, services and processes using I4.0 technologies that respect green economy, green transition and sustainability concepts. The described initiative promotes the transition of the economic activities towards a circular economy-based model through the reconversion of the industrial productive activities with the support of the digitalisation process.

\section{CONCLUSIONS}

Small and medium-sized enterprises are a focal point in shaping enterprise policy in the European Union, and they do need support in becoming more competitive by improving their business processes, products and services using digital technology. The article presented digital transformation towards Industry 4.0 from a regional innovation system (RIS) and policy perspective to improve regional innovation. In the research process, the descriptive analysis focused on cases as examples of ERDF-based initiatives that support the Industry 4.0 transfer of businesses, SMEs in particular.

Examples of effective policy instruments reinforcing Industry 4.0 absorption by SMEs that have been already successfully implemented in European regions are Industry 4.0-oriented Platforms, Digital Innovation Hubs and incentives for $\mathrm{R} \& \mathrm{D}$ projects focused on green and digital transformation.

SMEs might feel threatened by Industry 4.0 and related technologies. Educational activities of the knowledge platforms, also DIHs, are crucial for businesses to respond to external changes and understand the benefits of such technologies. Companies are likely to reject new technologies without such knowledge since they fail to understand their potential and benefits. Therefore, it is important to develop the ERDF-based policy instruments to support entrepreneurs in the transition process and serve as a guide in the adjustment to the challenges of Industry 4.0, particularly in the area of staff training and the implementation of technological processes.

Digital Innovation Hubs are another instrument for boosting the uptake of I4.0 among SMEs by promoting multi-actor collaborative platforms and placebased collaboration alliances that respond to local/ regional contextual specificities and demands.

Also, the regional and national support financed from structural funds for $\mathrm{R} \& \mathrm{D}$ projects is an effective way to help regions/countries invest in the green and digital transition through adopting innovative and sustainable solutions aimed at reconverting productive and industrial activities within the circular economy. The projects and financial aid can boost the economic development and competitiveness of companies, including SMEs, in need of investments and incentives for $\mathrm{R} \& \mathrm{D}$ activities.

It is significant to highlight successful cases of how specific policy instruments can help in boosting the digitalisation of SMEs and enable the transformation potential by dealing with main challenges hampering their diffusion, new technologies, products, services, or business models. The learning potential and inspirations embedded in presented interregional exchanges could result in the uptake of good practice by SMEs and policymakers aiming to speed up the diffusion of I4.0 technologies and thus enable the delivery of innovation within regional supply chains.

\section{ACKNOWLEDGEMENTS}

The results presented in this paper were reached with the help of funding from the European Regional Development Fund under the Interreg Europe programme (project acronym: SMARTY). The project mainly aims to improve the ability to implement policies supporting SME innovation projects that adapt Industry 4.0 solutions in line with regional strategies of intelligent specialisation.

The publication of the article for 11th International Conference on Engineering, Project, and Production Management - EPPM2021 was financed in the framework of the contract no. DNK/ SN/465770/2020 by the Ministry of Science and Higher Education within the "Excellent Science" programme.

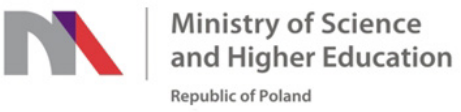

\section{LITERATURE}

Alcacer, V., \& Cruz-Machado, V. (2019). Scanning the industry 4.0: A literature review on technologies for manufacturing systems. Engineering Science and Technology, an International Journal, 22(3), 899-919. doi: 10.1016/j.jestch.2019.01.006

Atzori, L., Iera, A., \& Morabito, G. (2010). The internet of Things: A survey. Computer Networks, 54(15), 2787 2805. doi: 10.1016/j.comnet.2010.05.010

Azevedo, A., \& Almeida, A. H. (2021). Grasp the Challenge of Digital Transition in SMEs - A Training Course Geared towards Decision-Makers. Education Sciences, 11,151 . doi: 10.3390/educsci11040151 
Beier, G., Ullrich, A., Niehoff, S., Reißig, M., \& Habich, M. (2020). Industry 4.0: How it is defined from a sociotechnical perspective and how much sustainability it includes - A literature review. Journal of Cleaner Production, 259, 120856. doi: 10.1016/j. jclepro.2020.120856

Borowicz, A. (2021). Does the New Industrial Strategy for Europe Follow the Path of the Concept of Industry 4.0? Studia Europejskie - Studies in European Affairs, 1(2021), 85-102.

Davies, R. Industry 4.0. Digitalisation for productivity and growth, European Parliament. Retrieved from https://www.europarl.europa.eu/RegData/etudes/ BRIE/2015/568337/EPRS_BRI(2015)568337_ EN.pdf

Digital Innovation Hubs Working Group (2018). Report. Retrieved from https://ec.europa.eu/futurium/en/ system/files/ged/dihs_access_to_finance_report_final.pdf

European Commission (2018). Integration of Digital Technology Digital Economy and Society Index Report.

European Commission (2020). A new Industrial Strategy for a globally competitive, green and digital Europe.

European Commission (2020). Communication from the Commission to the European Parliament, the Council, the European Economic and Social Committee and the Committee of the Regions, An SME Strategy for a sustainable and digital Europe.

European Commission (2020). Communication from the Commission. Europe 2020. A strategy for smart, sustainable and inclusive growth.

European Commission (2020). European Industrial Strategy.

European Commission. Entrepreneurship and Small and medium-sized enterprises (SMEs). Retrieved from https://ec.europa.eu/growth/smes_en

Galati, F., \& Bigliardi, B. (2019). Industry 4.0: Emerging themes and future research avenues using a text mining approach. Computers in Industry, 109, 100-113. doi: 10.1016/j.compind.2019.04.018

Going Digital - the Challenges facing European SMEs (2019). European SME Survey.

Hervas-Oliver, J.-L., Gonzalez-Alcaide, G., Rojas-Alvarado, R., \& Monto-Mompo, S. (2021). Emerging regional innovation policies for industry 4.0: analyzing the digital innovation hub program in European regions. Competitiveness Review, 31(1), 106-129. doi: 10.1108/CR-12-2019-0159

Horváth, D., \& Szabó, R. Z. (2019). Driving forces and barriers of Industry 4.0: Do multinational and small and medium-sized companies have equal opportunities? Technological Forecasting and Social Change, 146, 119-132. doi: 10.1016/j.techfore.2019.05.021

Ingaldi, M., \& Ulewicz, R. (2020). Problems with the Implementation of Industry 4.0 in Enterprises from the SME Sector. Sustainability, 12(1), 217. doi: 10.3390/ su12010217

Jovanovski, B., Seykova, D., Boshnyaku, A., \& Fischer, C. (2019). The Impact of Industry 4.0 on the Competitiveness of SMEs. IV International Scientific Conference - Industry 4.0, Burgas, Bulgaria.
Khaitan, S. K., \& McCalley, J. D. (2015). Design techniques and applications of cyberphysical systems: A survey. IEEE Systems Journal, 9(2), 350-365. doi: 10.1109/ JSYST.2014.2322503

Marchuk, Y. Challenges for adoption of Industry 4.0 by SMEs. Retrieved from https://id-norway.com/challenges-for-adoption-of-industry-4-0-by-sme/

Papadopoulos, G., Rikama, S., Alajääskö, P., Salah-Eddine, Z., Airaksinen, A., \& Luomaranta, H. (2020). Statistics on small and medium-sized enterprise. Retrieved from https://ec.europa.eu/eurostat/statistics-explained/index.php?title=Statistics_on_small_ and_medium-sized_enterprises

Prause, M. (2019). Challenges of Industry 4.0 Technology Adoption for SMEs: The Case of Japan. Sustainability, 11(9), 5807. doi: 10.3390/su11205807

Probst, L., Lefebvre, V., Martinez-Diaz, C., Bohn, N. U., Klitou, D., \& Conrads, J. (2018). Digital Transformation Scoreboard: EU business go digital: opportunities, outcomes and uptake. European Union.

Ramalingham, B., Faith, B., Hernandez, K., Prieto Martin, P., \& Roberts, T. (2017). From Simple Fixes to Systemic Enablers: The Future of Digital Development. Brighton: IDS. Retrieved from https://opendocs.ids. ac.uk/opendocs/handle/20.500.12413/14296

Rauch, E., Matt, D. T., Brown, C. A., Towner, W., Vickery, A., \& Santiteerakul, S. (2018). Transfer of Industry 4.0 to Small and Medium Sized Enterprises. Transdisciplinary Engineering Methods for Social Innovation of Industry 4.0, 7, 63-71. doi: 10.3233/978-161499-898-3-63

Saunila, M. (2020). Innovation capability in SMEs: A systematic review of the literature. Journal of Innovation \& Knowledge, 5(4), 260-265. doi: 10.1016/j. jik.2019.11.002

Sommer, L. (2015). Industrial revolution Industry 4.0: Are German manufacturing SMEs the first victims of this revolution? Journal of Industrial Engineering and Management, 8(5), 1512-1532. doi: 10.3926/ jiem. 1470

Stake, R. E. (1995). The Art of Case Study Research: Perspective in Practice. London: Sage

Teegavarapu, S., Summers, J., \& Mocko, G. (2008). Case Study Method for Design Research: A Justification. Proceedings of the ASME Design Engineering Technical Conference, 4. doi: 10.1115/DETC2008-49980

United Nations Environment Programme Towards a Green Economy: Pathways to Sustainable Development and Poverty Eradication (2011). Nairobi Kenya.

Yu, F., \& Schweisfurth, T. (2020). Industry 4.0 technology implementation in SMEs - A survey in the Danish-German border region, International Journal of Innovation Studies, 4(3), 76-84. doi: 10.1016/j. ijis.2020.05.001 